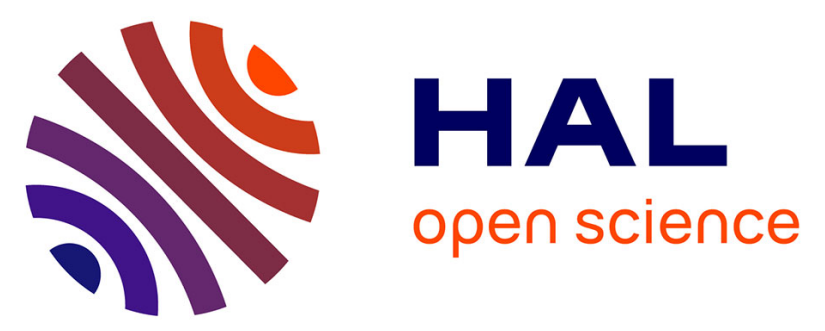

\title{
EFGR-mutant lung adenocarcinoma and Li-Fraumeni syndrome: Report of two cases and review of the literature.
}

Charles Ricordel, Marie Labalette-Tiercin, Alexandra Lespagnol, Mallorie

Kerjouan, Catherine Dugast, Jean Mosser, Benoit Desrues, Hervé Léna

\section{To cite this version:}

Charles Ricordel, Marie Labalette-Tiercin, Alexandra Lespagnol, Mallorie Kerjouan, Catherine Dugast, et al.. EFGR-mutant lung adenocarcinoma and Li-Fraumeni syndrome: Report of two cases and review of the literature.. Lung Cancer, 2015, 87 (1), pp.80-4. 10.1016/j.lungcan.2014.11.005 . hal-01092877

\section{HAL Id: hal-01092877 https://hal-univ-rennes1.archives-ouvertes.fr/hal-01092877}

Submitted on 9 Dec 2014

HAL is a multi-disciplinary open access archive for the deposit and dissemination of scientific research documents, whether they are published or not. The documents may come from teaching and research institutions in France or abroad, or from public or private research centers.
L'archive ouverte pluridisciplinaire HAL, est destinée au dépôt et à la diffusion de documents scientifiques de niveau recherche, publiés ou non, émanant des établissements d'enseignement et de recherche français ou étrangers, des laboratoires publics ou privés. 


\section{$\underline{E F G R \text {-mutant lung adenocarcinoma and Li-Fraumeni syndrome: report of two cases }}$} and review of the literature.

C. Ricordel ${ }^{1}$, M. Labalette-Tiercin ${ }^{1}$, A. Lespagnol ${ }^{2}$, M. Kerjouan ${ }^{1}$, C. Dugast ${ }^{3}$, J.Mosser $^{2}$, B. Desrues $^{1}$, H. Léna ${ }^{1}$

${ }^{1}$ Department of Respiratory Medicine, Pontchaillou Hospital, Rennes 1 University, 2 rue Henri-Le-Guilloux, 35033 Rennes cedex 9, France

${ }^{2}$ Molecular Genetics and Genomics department, Pontchaillou Hospital, Rennes 1 University, 2 rue Henri-Le-Guilloux, 35033 Rennes cedex 9, France

${ }^{3}$ Department of Clinical Genetics, South Hospital, Rennes 1 University, 16 Boulevard de Bulgarie, 35200 Rennes,France

Correspondence to:

Hervé Léna

Service de pneumologie, CHU de Rennes,

2 rue Henri-Le-Guilloux, 35033 Rennes cedex 9

Tel : 02.99.28.24.78-Fax : 02.99.28.24.80

herve.lena@chu-rennes.fr

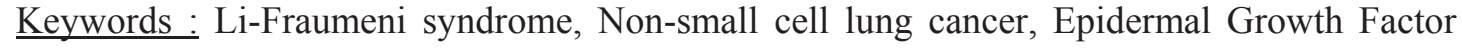
Receptor, Tyrosine Kinase Inhibitor, Molecular biology, Genetic predisposition to cancer 


\section{Abstract :}

We report two cases of non-smoker patients diagnosed with EGFR-mutated lung adenocarcinoma and bearing germinal TP53 gene mutation, also known as Li-Fraumeni syndrome (LFS). We describe for the first time an EGFR-TKI resistance mutation in this population. Finally, we provide an analysis of discerning epidemiological data obtained from the IARC database and from all the published cases of EGFR-mutated lung cancer in TP53 germline mutation carriers. 


\section{Introduction}

Li-Fraumeni syndrome (LFS) was initially described in the late 60's, based on the report of four families with high tumor occurrence [1]. This condition has been characterized by an autosomal dominant predisposition to various malignancies. The principal localizations are sarcomas, gliomas and breast carcinomas. Direct involvement of germline TP53 gene mutations has emerged approximately two decades after the primary description [2]. In most cases, mutation of the TP53 tumor suppressor gene result in a loss-of-function of p53 protein, leading to alterations in DNA repair, apoptosis cell-cycle control and consequently genome instability [3]. A worldwide database is now collecting both somatic and germline TP53 mutation on International Agency for Research on Cancer (p53.iarc.fr). Despite growing knowledge about LFS, prevalence of lung cancer is still unknown in this population but an increased risk has been described in observational studies [4]. Moreover, the literature is still scarce regarding the molecular abnormalities of lung neoplasms in this particular setting. An early report suggests an association between tumoral TP53 mutation and EGFR-driven lung cancer [5].

We report two cases of patients with LFS and EGFR-mutated lung adenocarcinoma, and provide the first description of resistance mutation to EGFR-TKI in this population. We highlight a potentially underreported association and emphasize the need for molecular alterations compiling in the particular setting of LFS. Reviewing all the published cases to date, we finally bring perspectives for clinical management. 


\section{Cases}

A fifty-five year old non-smoker man was diagnosed with a lower left leg deep venous thrombosis in December 2010. CT-scan evaluation revealed upper right lobe lung mass, abnormal mediastinal lymph nodes and two liver lesions. A liver biopsy confirmed the presence of a metastatic localization of a stage IV (T2a N3 M1b) lung adenocarcinoma. Eastern cooperative oncology group (ECOG) performance status was quantified to 0 at diagnosis. The patient was known to carry a LFS, because emergence of unusual childhood tumors in descendants led to germline TP53 gene sequencing a few years ago (TP53 germline mutation H179Y). First line chemotherapy with platinum and pemetrexed was administered, followed by EGFR-TKI (erlotinib). Three months later, paclitaxel was prescribed because of a cervical and mediastinal progression, which stabilized the disease for eight months. Symptomatic pleural effusion occurred and the patient clinically benefit from a re-challenge of platinum doublet chemotherapy. Approximately two years after diagnosis, CT-scan guided biopsy was performed on a new pulmonary nodule to assess tumoral molecular abnormality status and rule out transition to small cell lung cancer. The presence of an adenocarcinoma with both an EGFR exon 19 deletion (del2235-2249, delE745-A750) and an exon 20 T790M (c.2369C $>$ T) mutation was confirmed respectively by automated electrophoresis system (LabChip GX) and pyrosequencing (figure 1, panel A and B). A tumoral TP53 gene mutation was also found, similarly to the germline mutation previously described (data not shown). No mutation on HER2, PI3KCA, BRAF or KRAS genes or rearrangement of ALK gene was found. A fourth line of chemotherapy was proposed with an objective response observed after 4 cycles of carboplatin pemetrexed bevacizumab. The patient died a few months later from rapidly progressive pulmonary lymphangitic carcinomatosis (figure 1, panel C). 
A fifty-seven year old woman presented with a two month history of inflammatory lumbar pain in November 2008. MRI evaluation revealed a body lesion of L1 suspect of malignant origin. Needle bone biopsy confirmed the presence of a secondary metastasis of an upper left lobe lung adenocarcinoma. It was a stage IV (T2aN2M1b) disease and ECOG performance status was quantified to 0 at diagnosis. She never smoked and presented right breast carcinoma in 2002, treated by surgery and radiation. EGFR status was unknown at diagnosis because bone sample conditioning does not allow us to perform molecular analysis. After two cycles of cisplatin vinorelbin, the disease progressed, therefore erlotinib was prescribed. This therapy resulted in a significant and prolonged response. In october 2009, she was tested for germline TP53 mutation because her daughter was diagnosed with corticosurrenaloma. LFS was confirmed (TP53 mutation R273H). Thoracic progression occurred in November 2011 and the patient was enrolled in a phase 1 study evaluating an irreversible EGFR-TKI inhibitor (afatinib). Pleural metastasis was diagnosed in March 2012 and the targeted therapy was stopped. A surgical pleurodesis showed pleural localization of an adenocarcinoma with $E G F R$ exon 21 mutation L858R (c.2573T $>$ G) without T790M mutation, as assess pyrosequencing (figure 1, panel D). No mutation on HER2, PI3KCA, BRAF or KRAS genes or rearrangement of ALK gene was found. Consequently, a re-challenge with erlotinib resulted in a 5 month stable disease. The patient died from respiratory failure because of multiple pulmonary metastasis, more than four years after initial diagnosis (figure 1, panel E). 


\section{Discussion}

We report two LFS patients diagnosed with EGFR-mutated lung adenocarcinoma. Observational studies show that lung cancer belong to the spectrum of predisposed tumors in LFS [4]. According to Chompret criteria revised in 2009, a proband diagnosed with lung cancer before the age of 46 years and with at least one first-degree or second-degree relative with a core LFS tumor should be selected for a TP53 germline mutation testing. Our two patients do not meet these criteria and LFS was evocated because early-onset cancers in family history. Approximately $29 \%-35 \%$ of families with these criteria were shown to have TP53 germline mutations [6][7]. Importantly, recognition of LFS impacts the familial and personal cancer risk assessment, regarding potential radio-induced neoplasms. Thoracic oncologists should be aware of the possibility of this inherited predisposition syndrome especially when familial history of early-onset cancers is known. Our cases highlight the need for exhaustive medical family history interrogation when lung cancer is diagnosed, notably for young and non-smoker patients.

The literature is scarce regarding epidemiologic characteristics of lung cancer in LFS. The International Agency for Research on Cancer mutation database collecting the germline TP53 mutation reports various pathological subtypes in this restricted population [8]. Adenocarcinomas, including lepidic growth carcinomas (previously known as bronchoalveolar), represent the largest part of the confirmed pathological type when TP53 germline mutation is known (figure 2, panel A). In addition, majority of these tumors arise before the fifth decade and for a large part in women (figure 2, panel B). To date, this database do not contain molecular characteristic of these tumors. In our two patients, EGFR mutational status was unknown at diagnosis, but found during follow-up. Interestingly, co- 
occurrence of tumoral somatic TP53 mutations and EGFR mutations has been found in 34\% of lung adenocarcinomas in a recent international project [9]. Two retrospective studies tried specifically to assess this association, based on mixed genomic and immunohistochemical approaches [5][10]. Tumoral p53/arf pathway inactivation was observed in respectively $100 \%$ and $58.1 \%$ of $E G F R$-mutated lung cancers, supporting this hypothesis. Interestingly, a similar distribution of germinal and tumoral mutations is observed in the TP35 gene coding sequence, occurring preferentially in the DNA binding domain (exon 5 to 8). Nevertheless, it appears that all tumoral TP53 mutations are not equivalent regarding their intrinsic prognostic value. Indeed, a recent publication has described that non-disruptive TP53 mutations are associated with a worse outcome in EGFR-mutated NSCLC [11]. Moreover, a recent analysis of age of cancer onset from the IARC database suggests unequal repercussion of the different TP53 germline missense mutations [12]. Taken together, these clinical data suggest an important heterogeneity concerning the tumorigenic potential of the different subtype of TP53 mutations.

No exhaustive data concerning molecular biologic characteristics of lung cancers in the context of LFS has been published so far. Nevertheless, a growing number of publications reported EGFR mutant lung cancer in carriers of LFS suggesting a potential link between these two conditions [13][14][15][16]. Table 1 recapitulates important characteristics of the previous cases reported as well as our two patients. Consistent with IARC database, the majorities of tumors arise before the fifth decade and occur predominantly in woman. Interestingly, a majority of LFS patients harboring EGFR and/or ERBB2 mutated lung adenocarcinomas encompass good tumoral and clinical response to targeted therapy (except for the patient with T790M resistance mutation). The benefit appears to be quite similar than in non-LFS population with a progression-free survival of approximately one year. Some dedicated studies are needed to confirm this observation. As expected from clinical trials, 
rechallenge with EGFR-TKI after progression show no benefit in our second case, even in the absence of identified resistance mutation. Third generation TKI recently show promising antitumor activity, but current investigation are limited to the tumors with identified resistance mutation. Furthermore, we report for the first time acquisition of EGFR-TKI resistance mutation in the context of LFS. Familial cases of germline T790M may exist in $50 \%$ of these cases [17].It was ruled out in our first patient because allele frequency was not consistent with this hypothesis (around 7\%) and the mutation was not found in her daughter genome (data not shown). However, we cannot exclude that EGFR T790M mutation was not present at the time of diagnosis because reduced sample materials from hepatic needle-biopsy do not allow us to perform molecular biology. Still, these cases suggest a common natural history of resistance to TKI than in general population. In LFS patients, as the first genetic hit is inherited, we argue that a second-hit, according Knudson hypothesis, can arise sooner in the time course of tumorigenesis. Interestingly, some authors incriminate radiation therapy or chemotherapy as a second hit. Notably, five of six LFS cases with EGFR-mutated lung adenocarcinoma were previously treated with chemotherapy or radiotherapy in a context of mammary malignancies. Even if a causative role remains to be demonstrated, benefice-risk assessment of radiotherapy should be carefully evaluated and discussed with patients in this particular setting.

In conclusion, thoracic oncologists should evoke LFS in the context of illegitimate lung cancer (young and non-smoker patients). EGFR mutation is frequently reported in the LiFraumeni setting, but epidemiological studies are needed to assess this potential association. Response to targeted therapy seems to be similar as in the general population. Arguably, we show for the first time that same resistance mechanism could arise in the LFS context.. 


\section{References}

[1] Li FP, Fraumeni JF. Soft-tissue sarcomas, breast cancer, and other neoplasms. A familial syndrome? Ann Intern Med 1969;71:747-52.

[2] Malkin D, Li FP, Strong LC, Fraumeni JF, Nelson CE, Kim DH, et al. Germ line p53 mutations in a familial syndrome of breast cancer, sarcomas, and other neoplasms. Science 1990;250:1233-8.

[3] Toledo F, Wahl GM. Regulating the p53 pathway: in vitro hypotheses, in vivo veritas. Nat Rev Cancer 2006;6:909-23.

[4] Malkin D. Li-fraumeni syndrome. Genes Cancer 2011;2:475-84.

[5] Cortot AB, Younes M, Martel-Planche G, Guibert B, Isaac S, Souquet P-J, et al. Mutation of TP53 and alteration of p14(arf) expression in EGFR- and KRAS-mutated lung adenocarcinomas. Clin Lung Cancer 2014;15:124-30.

[6] Bougeard G, Sesboüé R, Baert-Desurmont S, Vasseur S, Martin C, Tinat J, et al. Molecular basis of the Li-Fraumeni syndrome: an update from the French LFS families. J Med Genet 2008;45:535-8.

[7] Gonzalez KD, Noltner KA, Buzin CH, Gu D, Wen-Fong CY, Nguyen VQ, et al. Beyond Li Fraumeni Syndrome: clinical characteristics of families with p53 germline mutations. J Clin Oncol Off J Am Soc Clin Oncol 2009;27:1250-6.

[8] Petitjean A, Mathe E, Kato S, Ishioka C, Tavtigian SV, Hainaut P, et al. Impact of mutant p53 functional properties on TP53 mutation patterns and tumor phenotype: lessons from recent developments in the IARC TP53 database. Hum Mutat 2007;28:622-9. 
[9] Clinical Lung Cancer Genome Project (CLCGP), Network Genomic Medicine (NGM). A genomics-based classification of human lung tumors. Sci Transl Med 2013;5:209ra153.

[10] Mounawar M, Mukeria A, Le Calvez F, Hung RJ, Renard H, Cortot A, et al. Patterns of EGFR, HER2, TP53, and KRAS mutations of p14arf expression in non-small cell lung cancers in relation to smoking history. Cancer Res 2007;67:5667-72.

[11] Molina-Vila MA, Bertran-Alamillo J, Gasco A, Mayo-de-Las-Casas C, SanchezRonco M, Pujantell-Pastor L, et al. Nondisruptive p53 mutations are associated with shorter survival in advanced non-small-cell lung cancer patients. Clin Cancer Res Off J Am Assoc Cancer Res 2014.

[12] Xu J, Qian J, Hu Y, Wang J, Zhou X, Chen H, et al. Heterogeneity of Li-Fraumeni syndrome links to unequal gain-of-function effects of p53 mutations. Sci Rep. 2014 Feb $27 ; 4: 4223$.

[13] Bemis LT, Robinson WA, McFarlane R, Buyers E, Kelly K, Varella-Garcia M, et al. EGFR-mutant lung adenocarcinoma in a patient with Li-Fraumeni syndrome. Lancet Oncol 2007;8:559-60.

[14] Serra V, Vivancos A, Puente XS, Felip E, Silberschmidt D, Caratù G, et al. Clinical response to a lapatinib-based therapy for a Li-Fraumeni syndrome patient with a novel HER2V659E mutation. Cancer Discov 2013;3:1238-44.

[15] Jia Y, Ali SM, Saad S, Chan CA, Miller VA, Halmos B. Successful treatment of a patient with Li-Fraumeni syndrome and metastatic lung adenocarcinoma harboring synchronous EGFR L858R and ERBB extracellular domain S310F mutations with the panHER inhibitor afatinib. Cancer Biol Ther 2014;15. 
[16] Michalarea V, Calcasola M, Cane P, Tobal K, Izatt L, Spicer J. EGFR-mutated lung cancer in Li-Fraumeni syndrome. Lung Cancer Amst Neth 2014;85:485-7. doi:10.1016/j.lungcan.2014.06.017.

[17] Oxnard GR, Miller VA, Robson ME, Azzoli CG, Pao W, Ladanyi M, et al. Screening for germline EGFR T790M mutations through lung cancer genotyping. J Thorac Oncol Off Publ Int Assoc Study Lung Cancer 2012;7:1049-52. 


\section{Author contributions:}

CR, MLT, MK, HL and BD were responsible for the literature search. CR, MLT, MK and HL were responsible for figures. $\mathrm{CR}$ was responsible for data collection. $\mathrm{CD}, \mathrm{AL}$ and $\mathrm{JM}$ were responsible for molecular biology data collection and analysis. All authors were responsible for data interpretation, and writing and final approval of the article. CR takes responsibility for the paper as a whole.

\section{Acknowledgments:}

We would like to thanks Dr. H. Symington for valuable comments and suggestions to improve the quality of the paper. 


\section{Legends:}

\section{Figure 1:}

(A) EGFR exon 19 deletion diagnosed by automated electrophoresis system (LabChip GX, Perkin Elmer®). (B) EGFR T790M resistance mutation (ACG $\rightarrow$ ATG) as assessed by pyrosequencing of tumoral DNA. (D) EGFR L858R activating mutation (CTG $\rightarrow$ CGG) as assessed by pyrosequencing of tumoral DNA (*: indicate mutated nucleotide or deleted allele). (C, E) Evolution of the sum of the longest diameters for all targeted lesions based on CT-scan measurement during follow-up.

\section{Figure 2:}

(A) Pie chart of pathological types of lung neoplasm in germline TP53 mutation carriers $(\mathrm{n}=34)$ ( $\dagger$ : including the bronchioloalveolar carcinoma). (B) Diagram of age and sex repartition of lung cancer in LFS patients ( $\mathrm{n}=33$; age missing for one patient). Data extracted from the International Agency for Research on Cancer p53 mutation database [9].

\section{Table 1:}

Clinical and biological characteristics of LFS patients diagnosed with EGFR-mutated lung adenocarcinoma. Obtained from case reports published in the literature. (CR: complete response, PR: partial response, PD: progressive disease) 


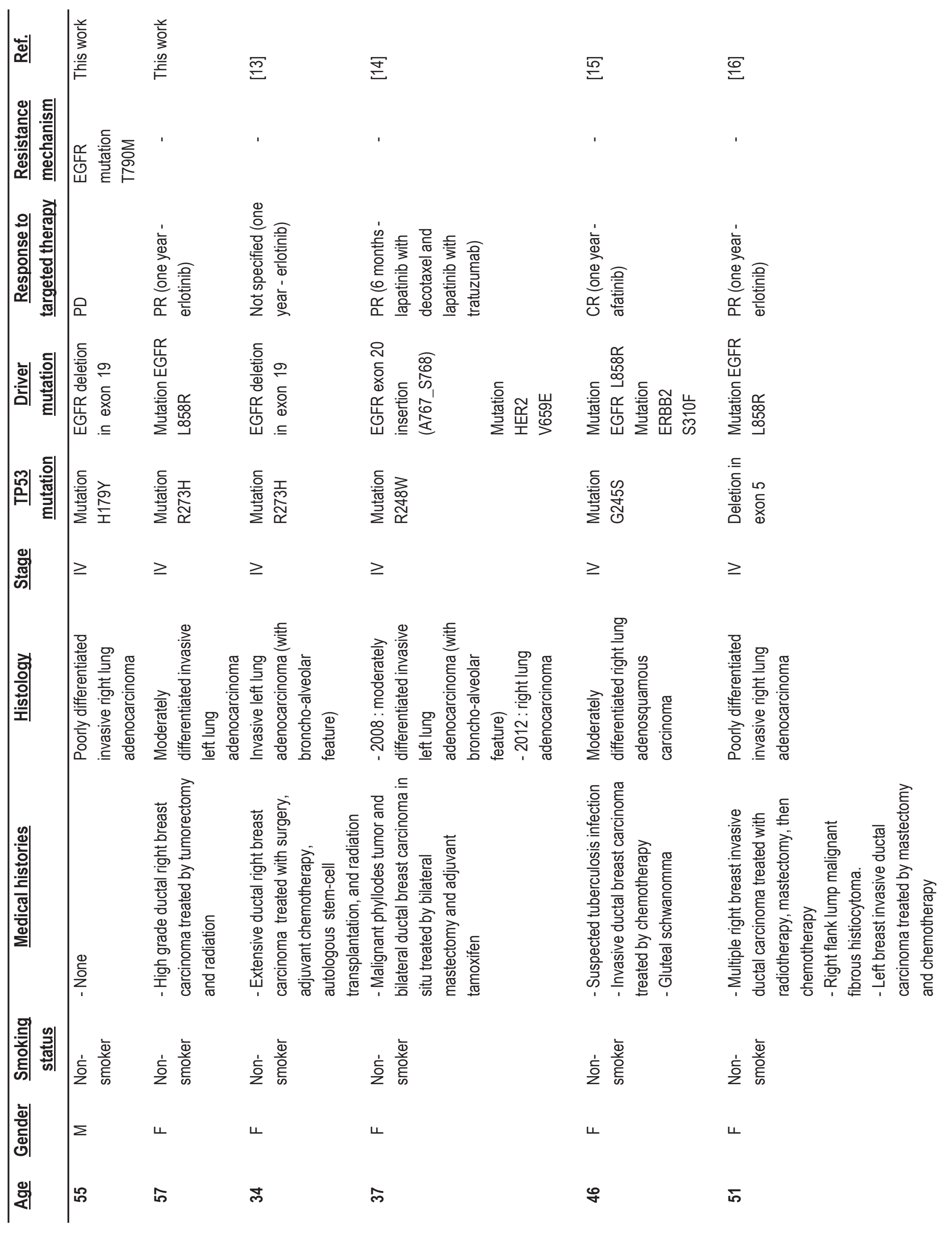




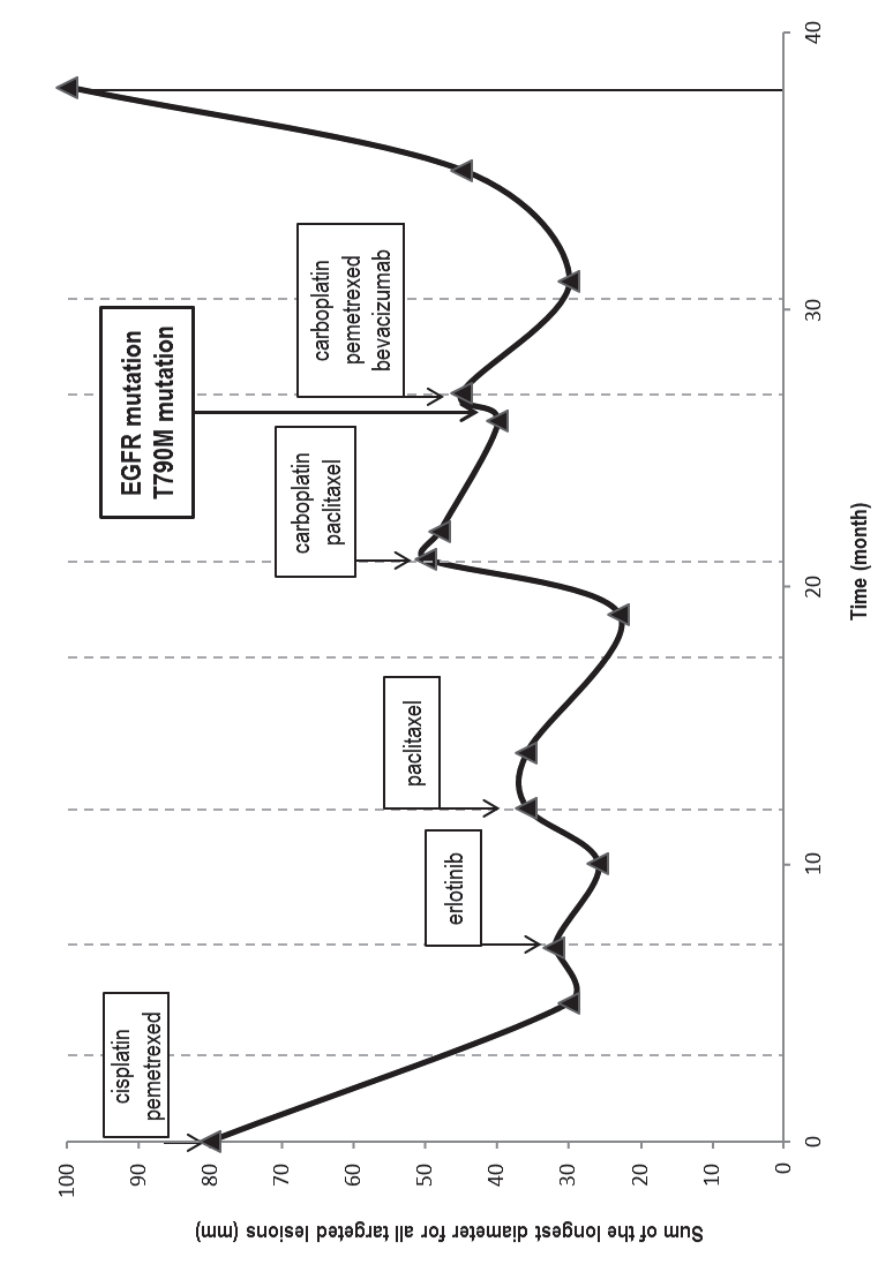

\section{0}
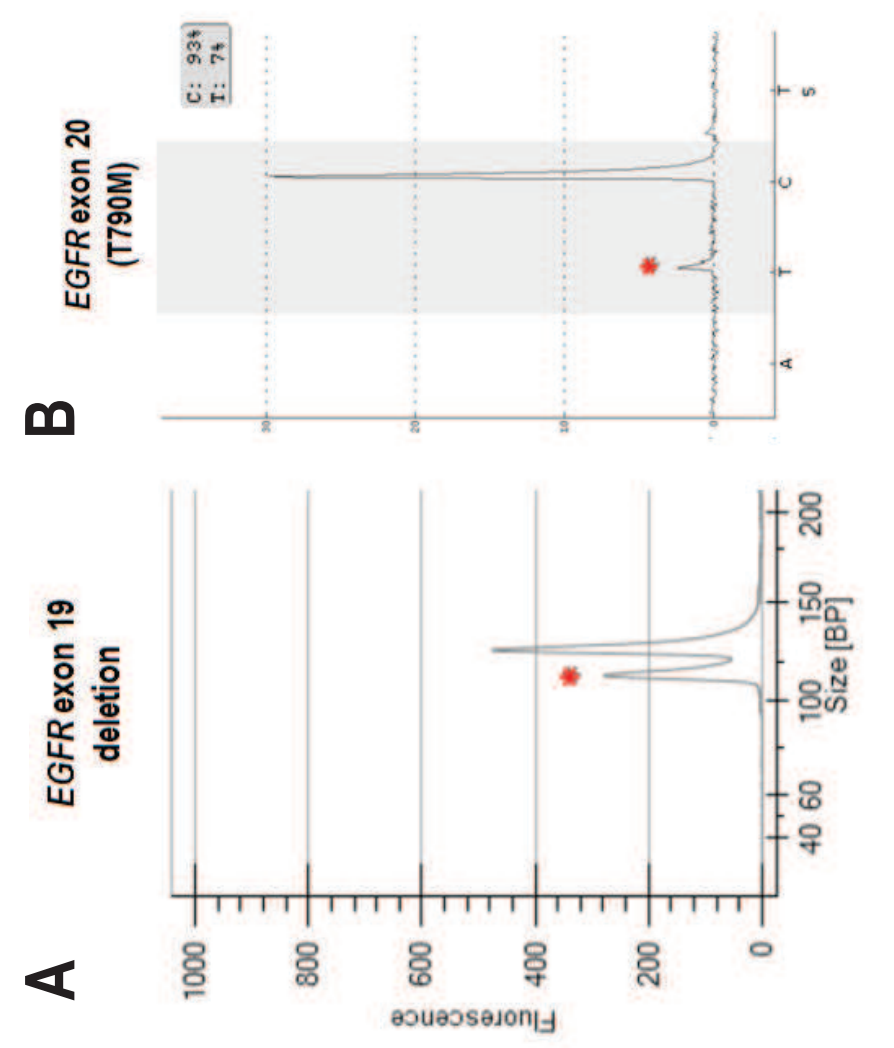

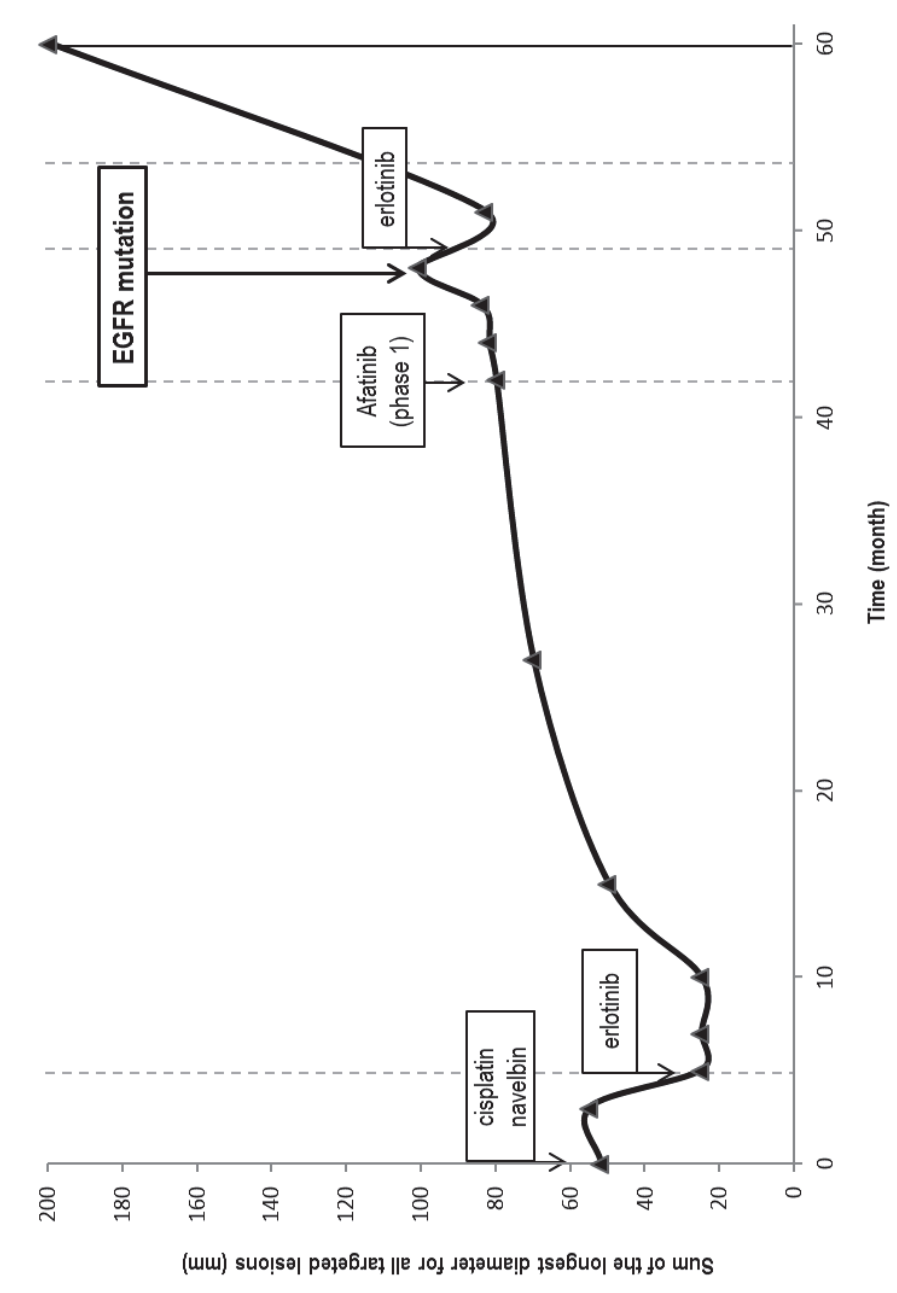

U

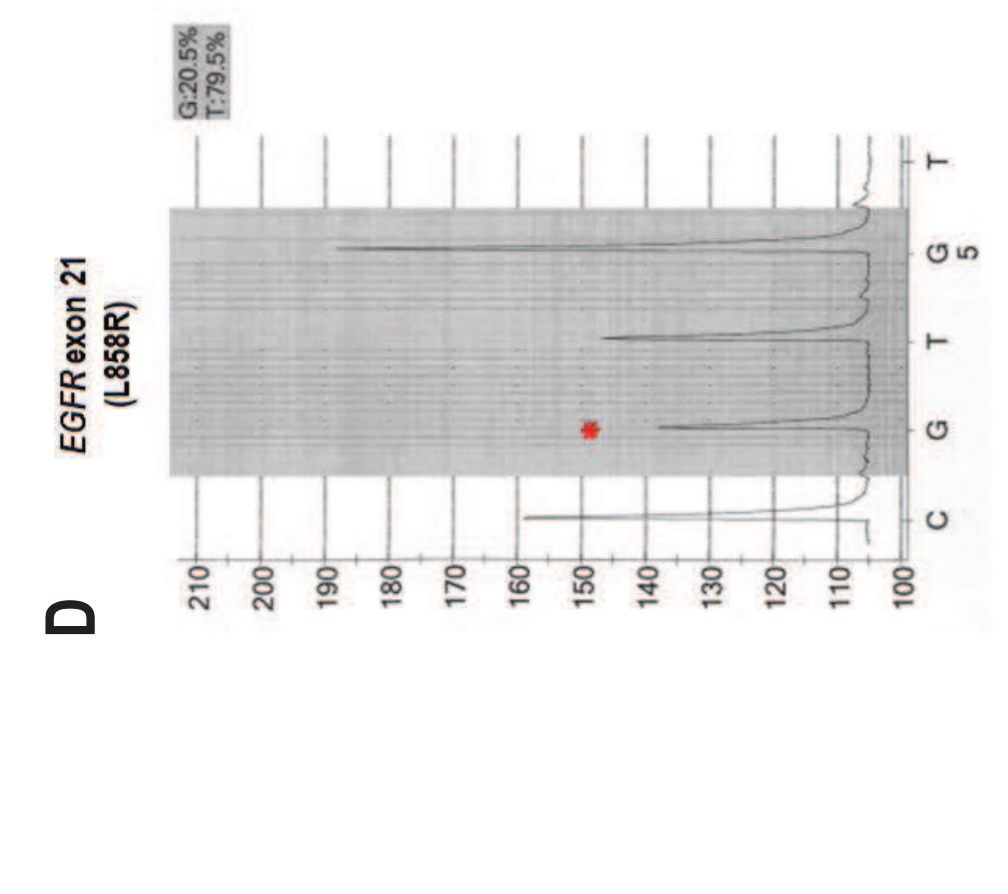



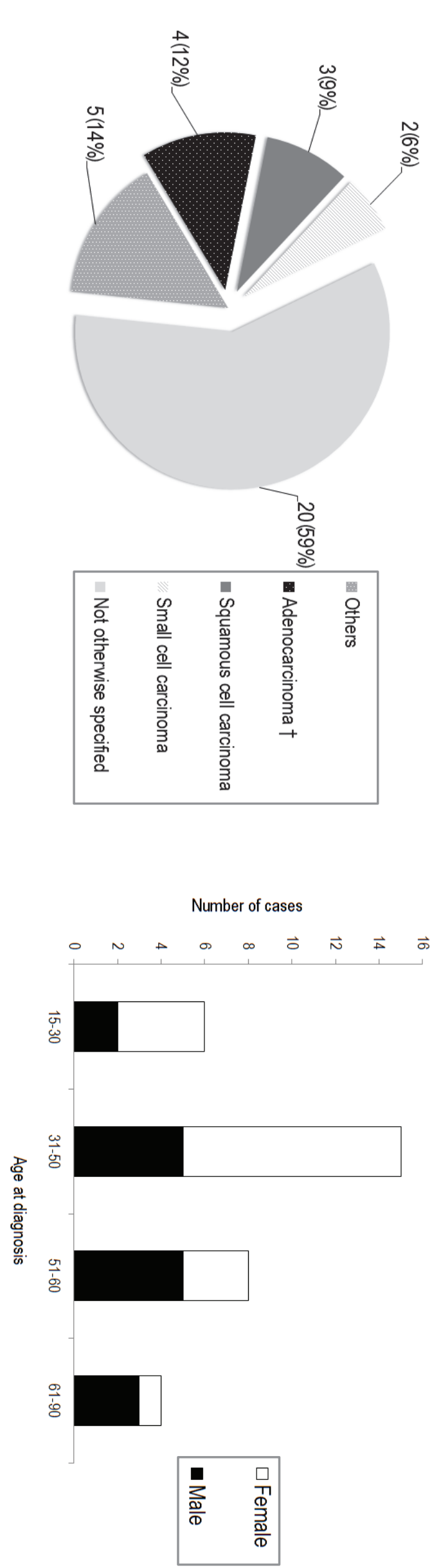